\title{
Preoperative Supraphysiological Testosterone in Older Men Undergoing Knee Replacement Surgery
}

\author{
John K. Amory, MD, $* /$ Howard A. Chansky, MD, ${ }^{+1 l}$ Kari L. Chansky, MS, \# \\ Matthew R. Camuso, MD, "Chris T. Hoey, PharmD, $\neq$ Bradley D. Anawalt, MD, *\|l \\ Alvin M. Matsumoto, MD, $*{ }^{*} \|$ and William J. Bremner, $M D, P h D /$
}

\begin{abstract}
OBJECTIVES: Older patients undergoing knee replacement surgery can recover more slowly than younger patients and require extended rehabilitation. Because administration of supraphysiological testosterone $(\mathrm{T})$ dramatically increases strength, we hypothesized that preoperative $\mathrm{T}$ therapy would improve functional recovery and reduce hospital stay in older men undergoing knee replacement surgery.
\end{abstract}

DESIGN: Double-blinded, placebo-controlled pilot trial.

SETTING: A Veterans Affairs orthopedics clinic and inpatient postoperative unit.

PARTICIPANTS: Twenty-five men, mean age 70 , undergoing elective knee replacement.

INTERVENTION: Preoperative, supraphysiological T administration $(600 \mathrm{mg} \mathrm{T}$ enanthate intramuscularly weekly for 4 weeks) or sesame oil placebo.

MEASUREMENTS: Length of hospital stay and functional ability by Functional Independence Measure (FIM) score.

RESULTS: Mean length of hospital stay \pm standard deviation was nonsignificantly reduced in the $\mathrm{T}$ group $(5.9 \pm$ 2.4 days vs $6.8 \pm 2.5$ days; $P=.15$ ). At postoperative Day 3 , there was a significant improvement in ability to stand (mean FIM score $5.2 \pm 1.0$ vs $4.0 \pm 1.1 ; P=.04$ ) and trends towards improvements in walking and stair climbing in the T group. There were no complications attributable to T therapy.

CONCLUSIONS: In older men undergoing knee replacement surgery, preoperative supraphysiological $\mathrm{T}$ adminis-

From the *Departments of Medicine, ${ }^{\circ}$ Orthopedics, $¥$ Pharmacy, and \$Geriatric Clinical Research Center, VA Puget Sound Health Care System, Seattle, Washington; "Departments of Medicine and "Orthopedics and Sports Medicine, University of Washington, Seattle, Washington; and "Fred Hutchinson Cancer Research Institute, Seattle, Washington.

The VA-Puget Sound Health Care System, Seattle Division, and the University of Washington, Seattle, Washington, supported this work.

Address correspondence to Dr. John K. Amory, MD, University of

Washington, Box 356429, 1959 NE Pacific Street, Seattle, WA 98195.

E-mail: jamory@u.washington.edu tration may confer some clinical benefit. Future studies using longer courses of preoperative $\mathrm{T}$ administration in larger numbers of older men undergoing knee replacement surgery are warranted. J Am Geriatr Soc 50:1698-1701, 2002.

Key words: arthritis; arthroplasty; FIM; rehabilitation

$\mathrm{K}$ nee replacement surgery is associated with beneficial outcomes in appropriately selected patients. More than 100,000 knee replacements are performed yearly in the United States, ${ }^{1}$ and $90 \%$ of these patients are aged 55 and older. ${ }^{2,3}$ Older patients have slower recovery of ambulatory function and strength in knee extensors than younger patients ${ }^{4,5}$ and are more likely to require prolonged hospitalization or inpatient rehabilitation postoperatively. ${ }^{4}$

Levels of testosterone (T) fall as men age, ${ }^{6}$ and supplementation with $\mathrm{T}$ can improve strength in older hypogonadal men. ${ }^{7}$ Recently, $T$ was shown to improve rehabilitation outcomes in older men with low-normal serum $\mathrm{T}$ levels during an 8 -week inpatient rehabilitation stay. ${ }^{8}$ Muscle strength and protein synthesis occur shortly after administration of exogenous $\mathrm{T},{ }^{9}$ and relatively low dosages of $\mathrm{T}$ result in improved strength after 1 month in older men. ${ }^{10}$ In young men, supraphysiological dosing of $\mathrm{T}$ enanthate results in dramatic exercise-independent increases in strength, muscle size and fat-free body mass without adverse affects on lipids, prostate-specific antigen (PSA), mood or behavior. ${ }^{11,12}$

Because strength plays such a pivotal role in recovery from a joint replacement operation, we hypothesized that short-term supraphysiological $\mathrm{T}$ therapy might improve postoperative outcomes in older men undergoing knee replacement surgery. Therefore, we conducted a double-blind, placebo-controlled trial of 4 weeks of preoperative supraphysiological $\mathrm{T}$ in older men undergoing knee replacement surgery to compare length of hospital stay and measures of functional recovery in patients given preoperative $\mathrm{T}$ with those of patients receiving placebo and assess the safety of short-term preoperative supraphysiological $\mathrm{T}$ in older men. 


\section{SUBJECTS AND METHODS}

\section{Subjects}

Forty-two men were screened; 25 , with a mean age of 70 (minimum 58, maximum 86), met entry criteria, enrolled, and were studied. All subjects underwent a complete history and physical examination. Inclusion criteria were age of 55 and older, male, and willingness to comply with study procedures. Exclusion criteria included known prostate cancer (benign prostatic hyperplasia was acceptable), severe liver or kidney disease, substance abuse, or other significant musculoskeletal conditions that could interfere with postoperative ambulation and rehabilitation.

\section{Experimental Design}

All male patients at the Veterans Affairs Puget Sound Health Care System, Seattle Division, undergoing knee replacement over a 2-year period were offered enrollment. After informed consent was obtained, the study pharmacist randomized subjects using a random number sequence. Patients in the treatment group received $600 \mathrm{mg} \mathrm{T}$ enanthate (Schein Pharmaceuticals, New Rathway, NJ) in $3 \mathrm{~mL}$ of sterile sesame oil intramuscularly $21,14,7$, and 1 day before surgery. Placebo patients received $3 \mathrm{~mL}$ of sterile sesame oil intramuscularly on the same dates. The $\mathrm{Hu}$ man Subjects Committee of the University of Washington and the Veterans Affairs Research and Development Committee approved this study protocol.

\section{Measurements}

An investigator (JKA) blinded to study assignment and not involved in the decision to discharge the patient recorded length of hospital stay and the need for posthospitalization inpatient rehabilitation for each patient. Postoperative functional recovery was assessed using three measures from the Functional Independence Measure (FIM), a 7-point scale in which higher scores indicate greater function and independence. This scale is commonly used to describe functional recovery after joint-replacement surgery. ${ }^{13}$ The measures used tested ability to stand from a bed or chair, ambulation, and ability to climb stairs. FIM scores were recorded preoperatively 21 and 1 days before surgery and 3 days and 5 weeks postoperatively. A single investigator (JKA) who was blinded to study group assessed subjects' physical function and assigned FIM scores. Serum total T, hematocrit, glutamic oxaloacetic transaminase, creatinine, lipoproteins (total cholesterol, high-density lipoprotein (HDL), and low-density lipoprotein), and PSA were measured at baseline, preoperatively, and 5 weeks after surgery. In addition, $\mathrm{T}$, creatinine, and hematocrit were measured 3 days postoperatively. Measurements of $\mathrm{T}$ were performed using sensitive fluoroimmunoassays (Delfia, Wallac Oy, Finland). The sensitivity and mid-range intra- and interassay coefficients of variation were T: $0.5 \mathrm{nmol} / \mathrm{L}, 4.2 \%$, and $7.6 \%$, respectively.

\section{Statistical Analysis}

Analysis was performed on the 22 subjects who completed all aspects of the study; four patients discontinued participation in the study as described below. For functional recovery and length of hospital stay, comparisons between treatment groups were performed using a general linear model. Rates of discharge to a rehabilitation facility were compared using a chi-square test. Changes over time in laboratory values were compared between treatment groups using a nonparametric two-sample rank-sum test (MannWhitney). For all comparisons an $\alpha$ of .05 was considered significant.

\section{RESULTS}

\section{Subject Outcomes}

Twenty-five men enrolled in the study, and 22 completed every aspect of the study, with three dropping out. Two subjects (one in placebo group, one $\mathrm{T}$ group) decided against having surgery after randomization and were discharged from the study. One subject (placebo group) suffered postoperative lower extremity injury that prevented ambulation and recovery and was therefore excluded from analysis. There were no deaths during the study, and 24 of the subjects were alive and well 1 year after their surgery. An 81-year-old male (T group) died from established coronary artery disease 12 months after surgery.

\section{Length of Hospitalization and Functional Recovery from Surgery}

The length of stay for knee replacement surgery was nonsignificantly lower in the $\mathrm{T}$ group than in the placebo group (Table 1). Twenty percent of knee surgery patients who received $\mathrm{T}$ required inpatient rehabilitation, compared with $25 \%$ of patients who received placebo injections $(P=.5)$. There were no baseline or preoperative differences between the $\mathrm{T}$ and placebo groups in ability to stand, walk, or climb stairs as measured by FIM (Table 2). At postoperative Day 3, every patient had experienced a decrease from baseline in each FIM score. Three days after surgery, subjects in the T group were able to stand significantly better than those who received placebo (mean FIM score \pm standard deviation $=5.2 \pm 1.0$ vs $4.0 \pm 1.1 ; P=$ $.04)$. Subjects in the T group demonstrated a trend toward

Table 1. Characteristics of Older Men Receiving Testosterone or Placebo Before Knee Replacement Surgery

\begin{tabular}{lcc}
\hline \multicolumn{1}{c}{ Characteristic } & Testosterone & Placebo \\
& $(\mathrm{n}=10)$ & $(\mathrm{n}=12)$ \\
\hline Age, mean \pm SD & $72 \pm 10$ & $69 \pm 6$ \\
Length of hospitalization, mean \pm SD & $5.9 \pm 2.4$ & $6.7 \pm 2.5$ \\
Subjects requiring inpatient rehabilitation, $\mathrm{n}(\%)$ & $2(20)$ & $3(25)$ \\
\hline
\end{tabular}

$\mathrm{SD}=$ standard deviation. 
Table 2. Baseline and Postoperative Functional Status As Measured by the Functional Independence Measure (1-7 Points) in Older Men Undergoing Knee Replacement Surgery and Receiving Preoperative Testosterone or Placebo

\begin{tabular}{lcc}
\hline & $\begin{array}{c}\text { Testosterone } \\
(\mathrm{n}=10)\end{array}$ & $\begin{array}{c}\text { Placebo } \\
(\mathrm{n}=12)\end{array}$ \\
\cline { 2 - 3 } \multicolumn{1}{c}{ Activity } & \multicolumn{1}{c}{ Mean \pm Deviation } \\
\hline Standing & & \\
$\quad$ Baseline & $7.0 \pm 0.0$ & $6.9 \pm 0.3$ \\
Postoperative day 3 & $5.2 \pm 1.0^{*}$ & $4.1 \pm 1.1$ \\
Postoperative day 35 & $6.7 \pm 1.0$ & $6.8 \pm 0.4$ \\
Walking & & \\
Baseline & $6.8 \pm 0.2$ & $6.5 \pm 0.5$ \\
Postoperative day 3 & $4.9 \pm 1.2$ & $4.1 \pm 1.8$ \\
$\quad$ Postoperative day 35 & $6.9 \pm 0.2$ & $6.6 \pm 0.5$ \\
Stair climbing & & \\
Baseline & $6.3 \pm 0.5$ & $6.2 \pm 0.4$ \\
Postoperative day 3 & $1.8 \pm 2.6$ & $1.4 \pm 1.2$ \\
Postoperative day 35 & $6.4 \pm 0.5$ & $6.1 \pm 0.3$ \\
\hline
\end{tabular}

${ }^{\star} P<.05$ compared with placebo.

better FIM scores in walking and stair climbing than subjects receiving a placebo. In no case did subjects in the placebo group perform better in any measure of functional recovery than subjects in the $\mathrm{T}$ group. By postoperative Day 35 , the overall FIM score had returned to baseline or better in $31 \%$ of patients in the T group, compared with $18 \%$ of subjects in the placebo group $(P=.2)$.

\section{Hormonal Responses to Preoperative Androgens}

Mean baseline serum total $\mathrm{T}$ levels were similar between groups $(12.5 \pm 4.5 \mathrm{nmol} / \mathrm{L}$ in the $\mathrm{T}$ group and $13.0 \pm 6.1$ $\mathrm{nmol} / \mathrm{L}$ in the placebo group). Immediately before surgery, serum total $\mathrm{T}$ was $82.5 \pm 16.2 \mathrm{nmol} / \mathrm{L}$ in those receiving preoperative $\mathrm{T}$ and $12.7 \pm 4.6$ in those receiving placebo
$(P=.001)$. On postoperative Day 3 , serum total T levels had decreased in both groups, to $78.7 \pm 22.3 \mathrm{nmol} / \mathrm{L}$ in the $\mathrm{T}$ group and to $3.4 \pm 2.5 \mathrm{nmol} / \mathrm{L}$ in the placebo group $(P<.001$ compared with baseline and between groups). By 5 weeks postoperatively, serum total $\mathrm{T}$ was not significantly different from baseline: $14.1 \pm 5.7 \mathrm{nmol} / \mathrm{L}$ in the $\mathrm{T}$ group and $11.7 \pm 3.5$ in the placebo group $(P=$ NS between groups and compared to baseline).

\section{Laboratory Responses to Preoperative Androgens}

Preoperative hematocrit was significantly higher in the group receiving $\mathrm{T}(45 \pm 3.7 \%$ vs $41 \pm 3.8 \%, P<.05$ compared with baseline and between groups; Table 3$)$. In addition, there was a trend toward increased postoperative hematocrit in the $\mathrm{T}$ group on postoperative Days 3 and 35 compared with placebo. HDL cholesterol trended downward before surgery $(53 \pm 20 \mathrm{mg} / \mathrm{dL}$ to $42 \pm 17$ $\mathrm{mg} / \mathrm{dL}, P=.07)$ in the T group, but HDL levels returned to baseline by postoperative Day 35 . There were no significant changes in serum markers of kidney or liver function or in serum PSA in either group. No patient experienced worsening symptoms of urinary retention.

\section{DISCUSSION}

Our pilot study shows that preoperative supraphysiological $\mathrm{T}$ administration to older men undergoing knee replacement surgery tends to improve functional recovery and shorten postoperative stay. It is likely that the improvements seen were due to improvements in strength, but a beneficial effect of $\mathrm{T}$ on mood, motivation, or perception of physical function may also be important. There were no adverse events attributable to $\mathrm{T}$ administration, demonstrating that short-term supraphysiological $\mathrm{T}$ administration is likely to be safe in older men.

Knee replacement is an elective procedure typically performed in patients who are thought to be healthy and active enough to benefit from increased mobility. Other less-healthy populations of patients, such as those with hip fracture and poor strength, have a fairly high short-term

Table 3. Hematocrit, Kidney and Liver Function, Lipoproteins, and Serum Prostate Specific Antigen in Older Men Administered Preoperative Testosterone or Placebo Before Knee Replacement Surgery

\begin{tabular}{|c|c|c|c|c|c|c|c|}
\hline Treatment & \multicolumn{7}{|c|}{ Mean \pm Standard Deviation } \\
\hline Day of surgery & $45 \pm 3.1^{*}+$ & $1.1 \pm 0.2$ & $26 \pm 6$ & $173 \pm 28$ & $41 \pm 17$ & $95 \pm 27$ & $2.2 \pm 1.3$ \\
\hline Postoperative day 3 & $32 \pm 3.3^{*}$ & $1.0 \pm 0.3$ & not done & not done & not done & not done & not done \\
\hline Postoperative day 35 & $41 \pm 4.4$ & $1.1 \pm 0.3$ & $21 \pm 4$ & $166 \pm 25$ & $46 \pm 10$ & $92 \pm 27$ & $1.8 \pm 1.1$ \\
\hline \multicolumn{8}{|l|}{ Placebo $(n=12)$} \\
\hline Preoperative day 21 & $42 \pm 3.4$ & $0.9 \pm 0.3$ & $19 \pm 7$ & $197 \pm 50$ & $46 \pm 12$ & $116 \pm 39$ & $1.2 \pm 0.8$ \\
\hline Day of surgery & $41 \pm 2.8$ & $0.9 \pm 0.2$ & $24 \pm 11$ & $175 \pm 40$ & $43 \pm 13$ & $102 \pm 28$ & $1.2 \pm 0.9$ \\
\hline
\end{tabular}

${ }^{\star} P<.05$ compared with baseline; ${ }^{\dagger} P<.05$ compared with placebo. 
mortality rate ${ }^{14}$ and might derive a greater benefit from $\mathrm{T}$ administration perioperatively. Indeed, older men with hypogonadism have been shown to be at increased risk of hip fracture..$^{15}$ This increased risk of fracture is likely due to a combination of decreased muscle mass, decreased strength, and osteoporosis from decreased serum T. T therapy in this population might improve recovery by improving muscle mass and strength and preventing prolonged bed-ridden status.

An additional benefit of preoperative $T$ might be a decreased need for blood transfusions because of the preoperative increase in hematocrit mediated by $\mathrm{T}$-induced increases in erythropoietin production. Longer-term $\mathrm{T}$ administration may have an even more beneficial effect. Although our pilot study included too few subjects to observe an effect on transfusion rate, a recent larger study demonstrated that preoperative erythropoietin administration for 4 weeks resulted in similar increases in preoperative hematocrit and decreased the need for postoperative transfusion in patients undergoing total hip replacement. ${ }^{16}$

Knee replacement surgery has improved quality of life for many older patients. The surgery is generally safe, but there is a need for techniques to improve outcomes and speed recovery in older patients who undergo this procedure. We have demonstrated that preoperative supraphysiological T administration to older men undergoing knee replacement surgery appears to be safe and leads to improvements in some measures of postoperative recovery. Future studies of this approach using longer-term $\mathrm{T}$ administration are warranted.

\section{ACKNOWLEDGMENTS}

The authors would like to thank Dorothy McGuinness and Arlen Sarkissian for their technical assistance and Tom Collins for his physical therapy expertise.

\section{REFERENCES}

1. Haberman ET. Orthopedic aspects of musculoskeletal disease in the lower extremities. Clin Geriatr Med 1988;4:357-374.

2. Harris WH, Sledge CB. Total hip and total knee replacement (first of two parts). N Engl J Med 1990;323:725-731.

3. Harris WH, Sledge CB. Total hip and total knee replacement (second of two parts). N Engl J Med 1990;323:801-807.

4. Munin MC, Kwoh K, Glynn N et al. Predicting discharge outcome after elective hip and knee arthroplasty. Am J Phys Med Rehabil 1995;74:294-301.

5. Zavadak KH, Gibson KR, Whitley DM et al. Variability in the attainment of functional milestones during the acute care admission after total joint replacement. J Rheumatol 1995;22:482-487.

6. Harman SM, Metter EJ, Tobin JD et al. Longitudinal effects of aging on serum total and free testosterone levels in healthy men: Baltimore Longitudinal Study of Aging. J Clin Endocrinol Metab 2001;86:724-731.

7. Sih R, Morley JE, Kaiser FE et al. Testosterone replacement in older hypogonadal men: A 12-month randomized trial. J Clin Endocrinol Metab 1997;82: 1661-1667.

8. Bakshi V, Elliott M, Gentili A et al. Testosterone improves rehabilitation outcomes in ill older men. J Am Geriatr Soc 2000;48:550-553.

9. Griggs RC, Kingston W, Jozefowicz FR et al. Effects of testosterone on muscle mass and muscle protein synthesis. J Physiol 1989;66:98-503.

10. Urban RJ, Bodenberg YH, Gilkison C et al. Testosterone administration to elderly men increases skeletal muscle strength and protein synthesis. Am J Physiol 1995;269:E820-E826.

11. Bhasin S, Storer TW, Berman N et al. The effects of supraphysiologic doses of testosterone on muscle size and strength in normal men. N Engl J Med 1996;335:1-7.

12. Pope HG, Kouri EM, Hudson JI. Effects of supraphysiologic doses of testosterone on mood and aggression in normal men. Arch Gen Psychiatry 2000; 57:133-140.

13. Munin MC, Rudy TE, Glynn NW et al. Early inpatient rehabilitation after elective hip and knee arthroplasty. JAMA 1998;279:847-852.

14. Hannan EL, Magaziner J, Wang JJ et al. Mortality and locomotion 6 months after hospitalization for hip fracture. JAMA 2001;285:2736-2742.

15. Stanley HL, Schmitt BP, Poses RM et al. Does hypogonadism contribute to the occurrence of minimal trauma hip fracture in elderly men? J Am Geriatr Soc 1991;39:766-771.

16. Feagan BD, Wong CJ, Kirkley A et al. Erythropoietin with iron supplementation to prevent allogeneic blood transfusion in total hip joint arthroplasty. Ann Intern Med 2000;133:845-854. 